\title{
CREDO DE MIGUEL ÁNGEL ASTURIAS: UMA RELEITURA DO CREDO APOSTÓLICO
}

\section{CREDO BY MIGUEL ÁNGEL ASTURIAS: A RETELLING OF APOSTLES' CREED}

\author{
Rodrigo Conçole Lage ${ }^{1}$
}

UNISUL

\begin{abstract}
RESUMO
O objetivo deste artigo é estudar o Credo, poema do escritor guatemalteco Miguel Ángel Asturias Rosales, em sua relação intertextual com o chamado Credo apostólico. Com essa finalidade, dividimos nosso artigo em duas partes. Na primeira, apresentamos as origens e características do texto cristão. $\mathrm{Na}$ segunda, após um breve comentário sobre a produção poética de Asturias, analisamos o poema visando identificar o modo como ele apresenta uma releitura política dos princípios teológicos definidos no Credo apostólico. Em anexo, apresentamos uma tradução literal do poema.
\end{abstract}

PALAVRAS-CHAVE: Miguel Ángel Asturias; Credo Apostólico; Poesia Guatemalteca.

\begin{abstract}
The objective of this article is to study the Credo, poem by Guatemalan poet Miguel Ángel Asturias Rosales, in his intertextual relation with the so-called Apostles' Creed. To this end, we divided our article into two sections. In the first, we present the origens and characteristics of the Christian text. In the second, after a brief comment about the poetic production of Asturias, we analysed the poem aiming at identify the way he presents a political retelling of the theological principles defined in the Apostles' Creed. Annexed, we present a literal translation of the poem.
\end{abstract}

KEYWORDS: Miguel Ángel Asturias; Apostles' Creed; Guatemalan Poetry.

\section{INTRODUÇÃO}

O escritor guatemalteco Miguel Ángel Asturias Rosales, ganhador do prêmio Nobel de Literatura de 1967, é amplamente conhecido por seus romances. O interesse do público e da crítica por esses livros fez com que, muitas vezes, dessem menos atenção ao restante do conjunto de sua produção. A constatação deste fato fez com que, depois de termos publicado um artigo sobre sua vida ${ }^{2}$, escolhêssemos como objeto de estudo um de seus poemas, o Credo. A escolha deste texto está relacionada ao fato de que existe uma "escassez ou ausência de trabalhos críticos sobre a produção poética asturiana” (MORENO DE LEÓN, 2011, p. 8, tradução nossa). Este desinteresse

1 Graduado em História (UNIFSJ). Especialista em História Militar (UNISUL). E-mail: rodrigo.lage@yahoo.com.br.

${ }^{2} \mathrm{O}$ artigo Vida e obra de Miguel Angel Asturias: as múltiplas faces de um escritor, publicado na revista eletrônica guari, em $2013 . \quad$ Disponível em: $<$ https://www.academia.edu/29476626/Vida e obra de Miguel \%C3\%81ngel Asturias as m $\%$ C $3 \%$ BAltiplas faces de um escritor>. Acesso em: 24 jul. 2018. 
[...] não tem permitido mostrar a natureza da mesma, seus valores estéticos, os âmbitos temáticos e suas relações com o conjunto de sua ampla obra, especialmente com sua narrativa. As causas pelas quais não se estuda a poesia de Asturias podem ser várias; uma delas, a ideia generalizada de que a sua produção poética não atinge a qualidade de sua obra narrativa; outra, a falta de interesse ou motivação dos investigadores pelo trabalho de análise e estudo do texto poético (MORENO DE LEÓN, 2011, p. 8, tradução nossa).

Como o poema escolhido está relacionado a um importante texto da literatura cristã, o chamado Credo Apostólico, decidimos estudar as relações intertextuais existentes entre os dois. Com esse objetivo, nós dividimos esse artigo em duas partes. Na primeira, nós falaremos do Credo pelo fato dele ter servido de inspiração ao poeta. Por isso, examinamos as origens dos credos, falamos sobre os mais importantes, discutimos a suposta origem apostólica, apresentamos a versão em latim acompanhada de uma tradução e apresentamos um resumo dele. Isso nos permitirá compreender a natureza da obra e ver como Asturias se apropriou do texto cristão para elaborar seu próprio credo. O que nos remete a questão da intertextualidade:

\begin{abstract}
A intertextualidade ocorre quando, em um texto, está inserido outro texto (intertexto) anteriormente produzido, que faz parte da memória social de uma coletividade. Como vemos, a intertextualidade é elemento constituinte e constitutivo do processo de escrita/leitura e compreende as diversas maneiras pelas quais a produção e recepção de um dado texto depende de conhecimentos de outros textos por parte dos interlocutores, ou seja, dos diversos tipos de ralações que um texto mantém com outros textos (KOCH, 2008, p. 86).
\end{abstract}

A partir dessa conceituação de intertextualidade, na segunda parte, iremos examinar as relações existentes entre os dois. Analisamos o poema comparando seus versos com os artigos do Credo de modo a identificar o modo como Asturias, tomando como foco a figura de bolívar e seus ideais, faz uma releitura política do texto cristão. Esperarmos que nosso trabalho possa contribuir para um melhor conhecimento de sua produção poética, para o entendimento da presença de elementos cristãos no conjunto de sua produção, assim como para um melhor entendimento dos seus ideais políticos. $\mathrm{Na}$ sequência, examinaremos o texto que inspirou o poema de Asturias, o Credo apostólico. Esperamos assim contribuir para um maior conhecimento de sua produção poética.

\title{
10 Credo apostólico: Origem e características
}

Dentro do cristianismo existem os sacramentos, atos por meio dos quais um cristão manifesta a sua relação com Deus. Para a Igreja Católica, a Ortodoxa e a Copta são sete, mas para os protestantes são apenas dois. Eles se dividem em sacramentos de iniciação (batismo, eucaristia e confirmação), de cura (penitência e unção dos enfermos) e de serviço (ordem sacerdotal e matrimônio). Dentre eles destacamos o batismo que é um rito de iniciação por meio do qual a pessoa se torna filho de Deus e é admitida como membro do corpo de Cristo, a Igreja.

Nos primeiros séculos do cristianismo, na chamada Patrística (séc. I-VIII d.C.3), os candidatos ao batismo (e, obviamente, os cristãos de modo geral) deveriam ser instruídos na fé cristã, aprendendo os ensinamentos de Jesus, para depois serem aceitos como membros. Para isso, surgiram fórmulas que resumissem os conteúdos da fé cristã e que pudessem, assim, ser facilmente aprendidas e transmitidas. Elas não eram escritas, só memorizadas. Mais tarde, durante o batismo, eram recitadas como uma declaração e confirmação daquilo que o candidato ao batismo acreditava, a chamada profissão de fé.

\footnotetext{
${ }^{3}$ Existem divergências em relação a datação do período da patrística. Seu início é normalmente datado entre o final do século I d.C. e início do II d.C. e seu término teria ocorrido no VIII d.C..
} 
Portanto, ao longo do tempo, a forma do credo diversificou-se. Alguns defendem que a versão mais antiga que conhecemos seria "a versão chamada Hippolytos (Credo Interrogativo de Hipólito [? - 256] em formato de perguntas e respostas). A forma atual foi primeiramente encontrada nos escritos de Cesário de Arles (470-543.)" (MEDEIROS FILHO, 2011, p. 45). O texto mais antigo que chegou até nós é uma versão em latim que foi incluída no Commentarius in symbolum apostolorum ${ }^{4}$, escrito pelo monge do séc. IV Tirânio Rufino, também conhecido como Rufino de Aquiléia 5 .

Outro texto importante é o Credo de Cesaréia, do bispo Eusébio de Cesaréia, que foi a base para o Credo de Nicéia, de 325 d.C. E, ainda no século IV, em 381, surge o chamado Credo nicenoconstantinopolitano, uma versão ampliada do que foi promulgado em Nicéia. Por fim, temos também o Símbolo Quicumque, também chamado de Credo de Atanásio devido a errônea atribuição do texto a Atanásio, bispo de Alexandria do século IV. Apesar de não serem os únicos, esses são os principais credos da antiguidade que chegaram até nós e nos permitem ter uma visão geral dos princípios básicos da fé tal como eram transmitidos aos fiéis.

No que diz respeito ao Credo apostólico, segundo Phillip Schaff, até o século dezessete protestantes e católicos aceitavam como verdadeira o relato, apresentado por Rufino, de que ele teria sido composto pelos doze apóstolos, no dia de Pentecoste, ou antes que se separassem, "para assegurar a unidade de ensino, cada um contribuindo com um artigo" (SCHAFF, 1877, p. 22). No Concílio de Ferrara, de 1438, Marco Eugenio, o arcebispo grego de Éfeso, declarou que as igrejas orientais não conheciam esse credo, "nem de sua origem apostólica" (QUASTEN, 1978, p. 32, tradução nossa). Essa foi a primeira vez que a autoria apostólica foi negada.

Mais tarde, "o humanista italiano Lorenzo Valla negou enfaticamente a paternidade apostólica do Symbolum Apostolicum” (QUASTEN, 1978, p. 32). O fato dele não ser mencionado na Bíblia, nem nos escritos dos chamados Padres apostólicos (aqueles que produziram textos pouco tempo depois daquele em que se data a produção dos do Novo Testamento) e de todos os demais escritores da patrística, e sínodos, anteriores ao Concílio de Nicéia também são utilizados como uma prova contra a autoria apostólica. Contudo, apesar de todos os argumentos contrários, a autoria apostólica continuou tendo defensores, mesmo entre alguns teólogos protestantes ${ }^{6}$.

Uma tese intermediária é que parte da hipótese de uma elaboração progressiva: "Investigações recentes sobre este ponto provam suficientemente que seu conteúdo essencial data da era apostólica. A forma atual, contudo, foi desenvolvida gradualmente" (QUASTEN, 1978, p. 32, tradução nossa) De modo que ele afirma que "sua forma atual, que consta de doze artigos, não é anterior ao século VI” (QUASTEN, 1978, p. 32, tradução nossa). Essa é a ideia mais comumente aceita atualmente pelos que tratam do assunto. De que, tal como outros textos orais, ele foi sendo desenvolvido por diferentes pessoas até chegar ao formato que nós conhecemos hoje.

Seja como for, apesar do poema de Asturias ser uma releitura de texto cristão, não temos como saber qual foi a versão utilizada. O escritor pode ter se baseado numa tradução em espanhol, ou em qualquer outro idioma que ele conhecia, mas nada impede que possa ter se

\footnotetext{
${ }^{4}$ Outras obras sobre o credo foram escritas na antiguidade. Temos, por exemplo, o Expositio Symboli de Venâncio Fortunato, o De Fide et Symbolo liber unus de Agostinho de Hipona.

${ }^{5}$ Foi um teólogo e historiador que se destacou por ter traduzido para o latim muitas obras gregas dos chamados Pais da Igreja.

${ }^{6}$ Para maiores informações, consultar o livro de Schaff (1877, p. 23), que conclui sua exposição dizendo que a autoria apostólica "nunca deveria ser afirmada seriamente de novo" (SCHAFF, 1877, p. 23, tradução nossa).
} 
inspirado no texto latino original. Diante dessa dúvida, iremos apresentar o texto original em latim, base de todas as traduções e, em seguida, colocaremos uma versão em português, a que iremos utilizar em nosso estudo:

\section{Symbolum Apostolicum ${ }^{7}$}

1. Credo in Deum Patrem omnipotentem, Creatorem caeli et terrae,

2. et in Iesum Christum, Filium Eius unicum, Dominum nostrum,

3. qui conceptus est de Spiritu Sancto, natus ex Maria Virgine,

4. passus sub Pontio Pilato, crucifixus, mortuus, et sepultus,

5. descendit ad ínferos, tertia die resurrexit a mortuis,

6. ascendit ad caelos, sedet ad dexteram Dei Patris omnipotentis,

7. inde venturus est iudicare vivos et mortuos.

8. Credo in Spiritum Sanctum,

9. sanctam Ecclesiam catholicam, sanctorum communionem,

10. remissionem peccatorum,

11. carnis resurrectionem,

12. vitam aeternam.

Amen. (COMPÊNDIO, 2005, p. 31)

Em português:

\section{Credo Apostólico}

1. Creio em Deus Pai todo-poderoso, Criador do céu e da terra.

2. E em Jesus Cristo, seu único Filho, nosso Senhor;

3. que foi concebido pelo poder do Espírito Santo; nasceu da Virgem Maria;

4. Padeceu sob Pôncio Pilatos, foi crucificado, morto e sepultado;

5. Desceu à mansão dos mortos, ressuscitou ao terceiro dia;

6. Subiu aos céus; está sentado à direita de Deus Pai todo-poderoso,

\footnotetext{
${ }^{7}$ A versão do texto do Compêndio, ao contrário do que ocorre em outras versões, não apresenta uma divisão numerada dos doze pontos. Nós utilizamos aqui, e na tradução apresentada na segunda seção, a divisão numérica utilizada por Philip Schaff nas traduções para o inglês que ele inseriu no volume I do The creeds of Christendom, with a history and critical, p. 21.
} 


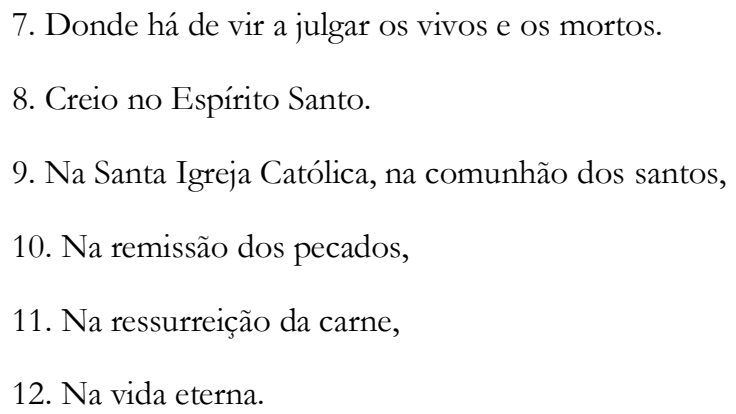

Amém (COMPÊNDIO, 2005, p. 31)

Por fim, ao analisarmos o poema, iremos comparar o teor dos versos com o que foi dito nos artigos do credo. Por isso, seria redundante comentá-los aqui. Diante deste fato, nos limitaremos a apresentar um breve resumo. Em síntese, o Credo é uma breve exposição da doutrina trinitária, talvez como uma forma de se combater as heresias que negavam a Trindade. Portanto, podemos divido em três partes. A primeira é dedicada ao Pai e a criação do mundo (1); a segunda aborda o Filho e o julgamento final (2-7); e a terceira trata do Espírito Santo, da santificação e salvação (8-12). Maiores detalhes serão apresentados na próxima seção, durante a análise:

\section{Credo de Miguel Ángel Asturias: Uma releitura política do Credo Apostólico}

A importância e a qualidade literária dos romances e contos de Asturias destacam-se em relação ao restante de sua produção. Consequentemente, suas peças de teatro, ensaios, textos jornalísticos, cartas e poemas são, em maior ou menor grau, menos conhecidos. O que não quer dizer que sejam menos importantes, como pode-se comprovar por sua extensa produção poética que pode ser dividida em três grupos.

Primeiramente, temos publicadas em plaquetas as peças em versos, posteriormente incluída em Poesía. Sien de Alondra, Rayito de estrela: fantomima, de 1929, e Alclasán: fantomima, de 1940; e o libreto de ópera Émulo Lipolidón, de 1935. Os outros dois grupos englobam os poemas propriamente ditos, excluindo-se os publicados em revistas e jornais (como o $A B C$, El imparcial e o El nacional) e os inéditos que foram publicados nas Obras Completas. No primeiro, temos os que foram publicados em plaquetas: Sonetos, de 1936; Con el rehén en los dientes, de 1942; Anoche, 10 de marzo de 1543, de 1943; Bolivar: Canto al Libertador, de 1955; Nombre Custodio e Imagen Pasajera, de 1959; Sonetos de Italia, de 1965. No segundo, temos os livros ${ }^{8}$ propriamente ditos que são Poesía. Sien de Alondra, de 1949; Ejercicios poéticos en forma de sonetos sobre temas de Horacio, de 1951; Alto es el sur, de 1952; Clarivigilia primaveral, de 1967; Miguel Ángel Asturias, raíz y destino: Poesía inédita, de 1999.

Como não temos acesso às obras poéticas de Asturias nós iremos utilizar a versão da coletânea Un canto à Bolivar (Antologia poética), de 2012. este poema está incluído na edição das obras completas de 1964. Mas, segundo Ariel Batres V. (2015, p. 30), "Não foi incluído nas Obras completas. Tomo I, reedição de 1969". Não sabemos o motivo dessa exclusão. Ele também está presente no livro da Editorial Cultura intitulado Páginas de lumbre de Miguel Ángel Asturias, de 1999, organizado por Francisco Morales Santos, que teria situado a sua escrita em

\footnotetext{
${ }^{8}$ Em 1984 foi publicado, pela Plaza \& Janés Editores S.A., o livro Torotumbo que reúne a novela que dá título a obra, a peça La audiencia de los confines. crónica en tres andanz̧as e Mensajes índios, uma coleção de poemas.
} 
Caracas, no ano de 1955. Por fim, foi igualmente publicado na Antología poética, organizada por Enrique Noriega em 2003, pela Editorial Piedra. Finalmente, apresentamos o texto no original em espanhol:

\author{
Credo \\ ¡Credo en la Libertad, Madre de América, \\ creadora de mares dulces en la tierra, \\ y en Bolívar, su hijo, Señor Nuestro \\ que nació en Venezuela, padeció \\ bajo el poder español, fue combatido, \\ sintióse muerto sobre el Chimborazo, \\ resucitó a la voz de Colombia, \\ tocó al Eterno con sus manos \\ y está parado junto a Dios!
}

¡No nos juzgues, Bolívar, antes del día último,
porque creemos en la comunión de los hombres
que comulgan con el pueblo, sólo el pueblo
hace libres a los hombres, proclamamos
guerra a muerte y sin perdón a los tiranos
creemos en la resurrección de los héroes
y en la vida perdurable de los que como Tú,
Libertador, no mueren, cierran los ojos y se quedan velando (ASTURIAS, 2012. p. 97).

Ele é composto de duas estrofes com nove e oito versos brancos. É um dos poemas que Asturias escreveu com o tema da figura de Simón José Antonio de la Santísima Trinidad Bolívar Palacios y Blanco, mais conhecido como Simón Bolívar, o militar e político venezuelano que teve um importante papel nas guerras de independência que ocorreram na América Espanhola. Ao contrário do que acontece com outros poemas, não encontramos aqui: "As raízes nativas, os laços profundos com a antiga poesia pré-colombiana" (BELLINI, 2008, p. 1, tradução nossa). Pelo contrário, vamos encontrar uma intima ligação com a teologia cristã.

Contudo, essa ligação não representa uma valorização do pensamento, dos ideais cristãos. Pelo contrário, essa relação assume uma forma negativa, pelo modo como ela a subverte. Ou seja, num gesto de valorização do mundo no qual o poeta está inserido (com seus valores, sua história, seus ideais), ele se apropria do pensamento cristão para negá-lo, por meio da recriação de um novo ideal. O que Asturias apresenta é uma declaração de amor ao continente americano, mais 
especificamente a América espanhola da qual faz parte. Nesse sentido, o poema aqui estudado apresenta as mesmas características encontradas em outros poemas:

\footnotetext{
A sincera adesão do artista às vicissitudes de seu povo, às vísceras da sua terra, permitelhe introduzir na poesia uma sensibilidade, uma frescura de ritmo e de cor completamente inédita, não no sentido do pitoresco, mas para salientar um pouco, como contraste, numa permanente nota lírica, as perturbadoras cores da tragédia, por cima das quais levanta uma mensagem de esperança. O contínuo cruzamento de planos temporais - passado e presente - estabelece uma perspectiva evidente de redenção para o futuro (BELLINI, 2008, p. 1, tradução nossa).
}

Por outro lado, a utilização de elementos cristãos para subvertê-los, por razões críticas, é uma prática relativamente comum dentro do conjunto de sua produção. No Malandrón, por exemplo, o autor "dessacraliza a linguagem religiosa com o fim de ridicularizar a religião cristã e tudo o que ela representa" (CASTRO, 2007, p. 44). Devido à atuação da Igreja Católica no continente não é de se surpreender que, ao olhar para o passado, Asturias a veja de forma negativa e reflita esse ponto de vista no seu trabalho. Algo que está presente no modo como ele utilizou o Credo. Relação que começa pelo próprio título do poema.

Mas, como existem vários credos cristãos, a relação intertextual com o Credo apostólico fica mais clara à medida que formos comparando seus artigos com os versos do poema. Inicialmente, nos dois primeiros versos, lemos "Creio na Liberdade, Mãe da América, / criadora de mares doces na terra," (ASTURIAS, 2012. p. 97, tradução nossa). No inicio do primeiro artigo lemos "Creio em Deus Pai todo-poderoso," (COMPÊNDIO, 2005, p. 31). Se o cristianismo é uma religião de caráter patriarcal o eu poético polemiza ao substituir a figura paterna pela materna. É uma significativa inversão de valores.

\subsection{A intertextualidade no Credo: A leitura política de um texto cristão}

Como foi dito na introdução, a intertextualidade ocorre pela inserção de um texto em outro, sendo que ela pode ocorrer de diferentes modos:

a) Intertextualidade de forma e conteúdo: quando alguém utiliza, por exemplo, determinado gênero textual tal como a epopeia em um outro contexto não épico só para obter um efeito de sentido especial; b) Intertextualidade explícita: como no caso das citações, discursos diretos, referência documentadas com a fonte, resumos, resenhas; c) Intertextualidade com textos próprios, alheios ou genéricos: alguém pode muito bem situar-se numa relação consigo mesmo e aludir a seus textos, bem como citar textos sem autoria específica como provérbios etc. (MARCUSCHI, 2008, 131).

Nós pretendemos demostrar que, no caso do poema de Astúrias, ela é de forma e conteúdo. Observando os versos um e dois do poema vemos que o eu poético afirma a sua fé na liberdade: "Creio na Liberdade, Mãe da América, / criadora de mares doces na terra," (ASTURIAS, 2012. p. 97, tradução nossa). Eles remetem ao primeiro artigo do Credo que, do ponto de vista religioso, é uma afirmação da crença num Deus Pai onipotente: "Creio em Deus Pai todo-poderoso, Criador do céu e da terra." (COMPÊNDIO, 2005, p. 31). Sendo que, nos dois casos temos um ato de fé: "A fé é um ato enorme e decisivamente pessoal: é a nossa decisão mais pessoal. Porém, isso de modo algum a torna menos comunitária; muito pelo contrário, pois, no campo da fé, quanto mais cresce o pessoal, tanto mais cresce o comunitário" (GONÇALES FAUS, 2015, p. 29).

$\mathrm{O}$ eu poético escreve porque quer que aquilo em que acredita seja a crença da comunidade. E a primeira coisa a ser ensinada é que a liberdade é mãe porque deu à luz a América quando a libertou do domínio espanhol. Ela não é divina, mas humana. Ao mesmo tempo, é criadora, não no sentido que o cristianismo atribui a Deus, de criar algo do nada, o que 
deixa bem claro que ela não é onipotente. Ela cria algo a partir da matéria preexistente, daquilo que existe na natureza. O poema apresenta, portanto, uma visão evolucionista do universo na qual a liberdade é motor das transformações que ocorrem e que levam ao surgimento de tudo o que existe nela. Ou seja, ele recusa a ideia de um Deus criador todo-poderoso. Como prova de sua afirmação, o poeta utiliza como exemplo o surgimento dos mares dulces.

Eles nascem no continente americano quando os rios desembocam no mar e, com sua grandeza e impetuosidade, "fazem retroceder as águas do mar a dezenas de quilômetros longe das praias” (SÉJOURNÉ, 1994, p. 19, tradução nossa). Ou seja, não foram criados por uma divindade, mas pela liberdade com que os rios se movimentam e que pode ou não levar a sua criação. Se as palavras utilizadas nos dois textos são quase as mesmas, as ideias que estão por detrás delas são totalmente opostas. Oposição que irá se acentuar cada vez mais.

O terceiro verso, "e em Bolívar, seu filho, Nosso Senhor" (ASTURIAS, 2012. p. 97, tradução nossa), corresponde ao segundo ponto do Credo, "E em Jesus Cristo, seu único Filho, nosso Senhor;" (COMPÊNDIO, 2005, p. 31). O eu poético, numa postura totalmente anticristã, rejeita Jesus como filho de Deus, substituindo-o pela figura de Bolívar, o filho da Liberdade, de certo modo divinizando-o, como veremos logo à frente. A escolha de Bolívar está relacionada à sua trajetória política, que levou a ações como a fundação da Grã-Colômbia e a convocação do Congresso do Panamá, e que o levou a ser chamado de El Libertador.

\begin{abstract}
Simón Bolívar foi um sonhador. "El Libertador" não se contentou com a conquista da independência da Espanha, no século XIX. Queria mais para a sua pátria Venezuela e para o continente: a liberdade do jugo colonial e de todas as formas de dominação. Bolívar queria uma América Latina integrada, próspera, detentora de seu destino, livre das amarras (TONETO, 2006, p. 1).
\end{abstract}

Ao mesmo tempo, ao escolher Bolívar como o novo messias, Asturias demostra todo o seu amor pelo continente, assim como exalta a valorização do seu passado e de determinados valores. E se o cristianismo, como religião, tem como base os ensinamentos de Cristo, subtendese que os ensinamentos do líder político venezuelano devem ser o evangelho dos povos americanos. Assim, se a maior parte do Credo é dedicada à figura de Cristo, naturalmente o mesmo acontece com Bolívar. Na continuação, no quarto verso do poema, lemos: "que nasceu na Venezuela, padeceu” (ASTURIAS, 2012. p. 97, tradução nossa).

O quarto verso deveria corresponder ao terceiro artigo do Credo, mas aqui o poeta não foi muito fiel ao original. Ele é uma combinação do terceiro com o início do quarto. Além disso, se no terceiro lemos "que foi concebido pelo poder do Espírito Santo; nasceu da Virgem Maria;" (COMPÊNDIO, 2005, p. 31), o eu poético exclui a ideia de concepção divina, algo natural dentro desse contexto inicial do poema, no qual a uma rejeição ao divino. E se Jesus nasceu de uma mulher, dentro desse contexto de valorização e amor ao continente, se destaca o fato de que Bolívar é um filho da terra, tendo sido gerado pela liberdade na Venezuela.

O verso cinco, "sob o poder espanhol, foi combatido," (ASTURIAS, 2012. p. 97, tradução nossa), corresponde, com algumas limitações, ao quarto artigo do Credo: "Padeceu sob Pôncio Pilatos, foi crucificado, morto e sepultado;" (COMPENDIO, 2005, p. 31). O poema faz uma associação do poder do império espanhol com o poder do antigo Império Romano. Jesus e Bolívar foram perseguidos injustamente pelas autoridades políticas da época, mas só um não foi morto pelas autoridades da época. Assim, podemos dizer que a luta contra os poderes constituídos foi um momento importante, na trajetória dos dois, para a construção da imagem deles no imaginário popular. 
O sexto e o sétimo verso, "sentiu-se morto sobre o Chimborazo, / ressuscitou pela voz da Colômbia," (ASTURIAS, 2012. p. 97, tradução nossa), correspondem ao quinto artigo do Credo "Desceu à mansão dos mortos, ressuscitou ao terceiro dia;" (COMPÊNDIO, 2005, p. 31). Do ponto de vista histórico, ele nunca passou por esse tipo de situação no vulcão Chimborazo, que é a montanha mais alta do Equador. Pelo contrário, ao subir no monte ele disse: "Eu não sei o que Providência tinha disposto, mas ela inspira confiança ilimitada em mim" (SLATTA; GRUMMOND, 2003, p. 234-235, tradução nossa).

Além disso, outro acontecimento que pode ter servido de inspiração para este verso é o fato de Bolívar ter escrito em 1822 o poema Mi delirio sobre el Chimborazo. Não temos como saber qual dos dois pode ter-lhe servido de inspiração, mas o certo é que nenhum deles envolveu a situação dele se sentir morto. Vemos aqui, da parte do eu poético, um trabalho de mitologização de uma figura histórica. Como alguns estudiosos entendem que, em torno de Jesus, se formou todo um mito, Asturias pode ter feito o mesmo em relação a Bolívar como uma forma de negar a historicidade de certos relatos sobre a vida de Cristo.

Por outro lado, se Jesus ressuscitou por causa de sua natureza divina, Bolívar ressuscitou por sua ligação com o continente. Colômbia pode ser tanto uma referência à fundação da República da Grã-Colômbia quanto uma referência à luta pela independência da Colômbia. Provavelmente, ao falar em ressurreição, tenha em mente a série de fracassos, tal como o da Segunda República de Venezuela, que o levaram a refletir sobre as causas desses fracassos e como poderia obter uma independência duradoura. Foi a partir dessa situação que se desenvolveu a ideia de se fazer da Colômbia um país.

No sexto artigo do Credo lemos: "Subiu aos céus; está sentado à direita de Deus Pai todopoderoso," (COMPÊNDIO, 2005, p. 31). Ele, em menor grau, corresponde aos versos oito e nove do poema: “tocou o Eterno com suas mãos / e está parado junto a Deus!" (ASTURIAS, 2012. p. 97, tradução nossa). Se até então o texto tem um caráter antirreligioso o eu poético, agora, diviniza a Bolívar. Como os semideuses da mitologia grega, com o ato da fundação da Colômbia ele ascendeu à divindade, talvez uma metáfora para o país. Mas, ao contrário do que ocorre com o cristianismo, a relação entre Bolívar e Deus não é como a de Jesus, de pai e filho, mas de alguém que está junto, o que reforça a tese que o próprio país ou o continente é um deus.

Ao excluir do poema a palavra pai, Asturias cria um distanciamento entre os dois. O que não impede que ele assuma algum dos atributos de Cristo. Se o sétimo artigo diz que ele está no Céu "Donde há de vir a julgar os vivos e os mortos" (COMPÊNDIO, 2005, p. 31); o décimo verso também faz dele um juiz: "Não nos julgue, Bolívar, antes do último dia," (ASTURIAS, 2012. p. 97, tradução nossa). Se os cristãos devem ser julgados por seus pecados a ideia é de que os habitantes do continente americano devem ser julgados por não seguirem os ideais de Bolívar. A defesa desses ideais e a denúncia dos que se corromperam é um dos temas centrais de sua produção.

Por outro lado, mais uma vez polemizando com o cristianismo, não temos nenhum verso que se ajuste ao oitavo artigo do Credo: "Creio no Espírito Santo" (COMPÊNDIO, 2005, p. 31). Os versos onze, doze e treze dizem: "porque cremos na comunhão dos homens / que comungam com o povo, só o povo/ faz livres aos homens, proclamamos" (ASTURIAS, 2012. p. 97, tradução nossa). Eles são uma releitura do nono artigo no qual se afirma a crença: "Na Santa Igreja Católica, na comunhão dos santos," (COMPÊNDIO, 2005, p. 31). A partir desse artigo veremos que se acentuam as diferenças existentes entre o Credo e o poema.

Ambos os textos afirmam a necessidade da comunhão entre os homens, rejeitando, pelo menos em tese, qualquer tipo de divisão de classe. Assim como a Igreja Católica, como corpo 
místico de Cristo, deve ser uma, a nação também deve ser. Contudo, o eu poético defende que a única classe que verdadeiramente liberta os homens é o povo. Assim, a verdadeira comunhão só pode surgir se as demais classes comungarem com ele, e não o contrário. Por isso, no décimo artigo se confirma a crença "Na remissão dos pecados," (COMPÊNDIO, 2005, p. 31), pois essa unidade da igreja tem com um de seus alicerces o arrependimento do pecador.

Por outro lado, no décimo quarto verso, o eu poético proclama "guerra de morte e sem perdão aos tiranos" (ASTURIAS, 2012. p. 97, tradução nossa). Assim, ele deixa claro que, somente por meio da guerra, o povo pode conquistar a sua liberdade. Se o cristianismo diz que os pecados podem ser perdoados e com isso o pecador pode mudar de vida e fazer parte da Igreja, o eu poético rejeita totalmente essa ideia. A ideia de perdão está totalmente excluída, sendo a eliminação dos maus o caminho necessário para a construção da nação. A utilização de um texto cristão como base dessas afirmações é uma forma de reforçar seu radicalismo.

Mas, nos últimos versos as diferenças entre os dois textos se atenuam. No décimo primeiro artigo do Credo nós vemos a crença "Na ressurreição da carne," (COMPÊNDIO, 2005, p. 31). O eu poético, por sua vez, afirma: "cremos na ressurreição dos heróis" (ASTURIAS, 2012. p. 97, tradução nossa). Um dos dogmas do cristianismo é a ideia de que todos os mortos um dia serão ressuscitados, alguns para a salvação eterna e outros para a condenação eterna. Por outro lado, quando o eu poético afirma a sua crença na ressurreição podemos dizer que ela ocorre em sentido figurado, quando ele renasce na memória das gerações vindouras, transmitindo-lhes seus ideais.

O sentido figurado da ideia de ressurreição fica ainda mais claro nos dois últimos versos: "e na vida perdurável dos que como Tu, / Libertador, não morrem, fecham os olhos e ficam velando" (ASTURIAS, 2012. p. 97, tradução nossa). Eles foram baseados no último artigo do Credo, no qual se confirma a crença "Na vida eterna" (COMPÊNDIO, 2005, p. 31). Assim, mesmo estando morto, para o eu poético, Bolívar continua vivo, velando em espírito pelos povos do continente, exercendo o seu papel de salvador. O poema é um hino de louvor a Bolívar e a todos os que lutaram, ou lutarão, guiados por seus ideais.

\section{CONSIDERAÇÕES FINAIS}

Sendo o cristianismo uma religião que se apresenta como o único caminho de salvação para a alma humana ela tem como um de seus fundamentos a ideia de que deve ser pregada para toda a humanidade para que os homens possam se salvar. Por sua vez, Asturias, diante da situação política e social da América Latina, vê nos ideias de Bolívar o único caminho de emancipação do continente. Esse fato pode ter levado o escritor guatemalteco a utilizar um texto cristão como base para a confecção de um poema que ressaltasse a importância dos ideais do líder militar e político venezuelano.

Assim como, ao longo de sua história, os cristãos se viram obrigados a resumir os princípios básicos de seus ensinamentos, para que fossem facilmente assimilados pelos ouvistes. Asturias decidiu fazer o mesmo com os seus princípios políticos. Se, com o objetivo de sintetizar os princípios básicos de sua fé, foi elaborado o Credo Apostólico, Miguel Ángel Asturias também se viu na necessidade de elaborar seu próprio Credo, na qual a trindade (Pai, Filho e Espirito Santo) foi substituída pela dualidade (Liberdade e Bolívar). Na visão do autor, só a liberdade associada aos ideais de Bolívar poderá criar uma América verdadeiramente livre.

Como foi assinalado anteriormente, o poema aqui estudado foi uma das obras em que o autor fez uma releitura subversiva dos princípios cristãos por meio da intertextualidade, da apropriação da forma e do conteúdo do texto cristão. Acreditamos que novos estudos sobre o 
assunto, em outros textos, irão contribuir para um melhor conhecimento do papel do cristianismo dentro do conjunto de sua obra, assim como ajudar na identificação dos elementos que ele utilizou (dogmas, textos, etc.). Esperamos, assim, contribuir para um melhor conhecimento da produção de Asturias e motivar outros a estudá-lo.

\section{REFERÊNCIAS BIBLIOGRÁFICAS}

ASTURIAS, Miguel Ángel. Credo. In: V.V.A.A. (2012). Un canto a Bolívar (Antología poética). Caracas: Fundación Editorial El perro y la rana, 2012. p. 97.

BATRES V., Ariel. Miguel Ángel Asturias con la magia de los tempos, 2015. Disponível em: $<$ https://www.academia.edu/16999878/Miguel \%C3\%81ngel Asturias con la magia de los t iempos >. Acesso em: 20 jul. 2018.

BELLINI, Giuseppe. I "Sonetos venecianos" di Asturias. Biblioteca Virtual Miguel de Cervantes, 2008.2 Disponível em: $<$ http://www.cervantesvirtual.com/portales/giuseppe bellini/obra/i-sonetos-venecianos-diasturias--0/>. Acesso em: 28 jul. 2018.

CASTRO, Daniel Rodrigues de. 152 f. A obra de Miguel Ángel Asturias e o aspecto intercultural: choque de deuses, mitos e sabedoria. Dissertação (Mestrado em Letras Neolatinas) - Universidade Federal do Rio de Janeiro, Rio de Janeiro, 2007. Disponível em: $<$ www.letras.ufri.br/pgneolatinas/media/.../danielrodriguesdecastromestrado.pdf $>$. Acesso em: 28 jul. 2018.

COMPÊNDIO DO CATECISMO DA IGREJA CATÓLICA. São Paulo: Loyola, 2005.

GONÇALES FAUS, José I. Confio: comentário ao credo cristão. Petrópolis: Vozes, 2015.

KOCH, I. G. V. O texto e a construção dos sentidos. São Paulo: Contexto, 2001.

MARCUSCHI, L. A. Produção Textual, Análise de Gêneros e Compreensão. São Paulo: Parábola Editorial, 2008.

MEDEIROS FILHO, João. O Rosário de Nossa Senhora: História e Mensagem. $2^{\circ}$ edição. Rio de Janeiro: Letra Capital, 2003.

MORENO DE LEÓN, Jaime Francisco Enán. Visión poética del mundo maya em Clarivigilia primaveral de Miguel Ángel Asturias. Tese (Licenciatura em Letras) Universidad de San Carlos de Guatemala, Guatemala, 2011. Disponível em: <http://www.repositorio.usac.edu.gt/2004/>. Acesso em: 29 jul. 2018.

QUASTEN, Johannes. Patrologia I. Hasta el concilio de Nicea. Madrid: Biblioteca de Autores Cristianos, 1978.

SCHAFF, Philip. The creeds of Christendom, with a history and critical notes. Volume I. New York, London: Harper \& Brothers Publishers, 1877. Disponível em:

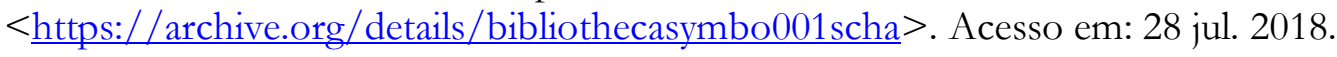

SÉJOURNÉ, Laurette. América Latina: Antiguas Culturas Precolombinas. Madrid, Siglo XXI de España Editores, 1994. 
SLATTA, Richard W.; GRUMMOND, Jane Lucas. Simon Bolivar's Quest for Glory. College Station: Texas A\&M University Press, 2003.

TONETO, Maria Bernardete. 115 f. O cerco rompido: Do monopólio dos meios de comunicação à participação popular no Brasil e Venezuela. Dissertação (Mestrado em Integração da América Latina) - Universidade de São Paulo, São Paulo, 2006. Disponível em: <http://www.teses.usp.br/teses/disponiveis/84/84131/tde-11102012-121054/pt-br.php>. Acesso em: 21 jul. 2018.

\section{Anexo}

\section{Credo}

Miguel Ángel Asturias

¡Credo en la Libertad, Madre de América, creadora de mares dulces en la tierra,

y en Bolívar, su hijo, Señor Nuestro

que nació en Venezuela, padeció

bajo el poder español, fue combatido,

sintióse muerto sobre el Chimborazo,

resucitó a la voz de Colombia,

tocó al Eterno con sus manos

y está parado junto a Dios!

¡No nos juzgues, Bolívar, antes del día último,

porque creemos en la comunión de los hombres

que comulgan con el pueblo, sólo el pueblo

hace libres a los hombres, proclamamos

guerra a muerte y sin perdón a los tiranos

creemos en la resurrección de los héroes

y en la vida perdurable de los que como Tú,

Libertador, no mueren, cierran los ojos y se quedan velando.

\section{Credo}

Miguel Ángel Asturias

Não nos julgue, Bolívar, antes do último dia, porque cremos na comunhão dos homens que comungam com o povo, só o povo faz livres aos homens, proclamamos guerra de morte e sem perdão aos tiranos cremos na ressurreição dos heróis e na vida perdurável dos que como Tu, Libertador, não morrem, fecham os olhos e ficam velando. 